\title{
Microsatellite DNA instability in nasal cytology of COPD patients
}

\author{
ALEXANDER D. KARATZANIS ${ }^{1}$, KATERINA D. SAMARA ${ }^{2}$, ELENI TZORTZAKI ${ }^{2}$, MARIA ZERVOU ${ }^{2}$, \\ EMMANUEL S. HELIDONIS ${ }^{1}$, GEORGE A. VELEGRAKIS ${ }^{1}$ and NIKOLAOS SIAFAKAS ${ }^{2}$ \\ ${ }^{1}$ Department of Otorhinolaryngology, Head and Neck Surgery; ${ }^{2}$ Department of Thoracic Medicine, \\ Medical School, University of Crete, Heraklion, Crete, Greece
}

Received November 16, 2006; Accepted January 4, 2007

\begin{abstract}
Genetic alterations in the microsatellite DNA level have been successfully detected in sputum samples of patients with COPD and have been shown to be disease specific. Furthermore, previous studies have shown that inflammation coexists in the nasal mucosa of patients with COPD. The aim of this study was to assess the presence of MSI in nasal cytological samples of patients with COPD comparing the results with sputum samples of the same individuals. Nasal brush samples, sputum samples obtained by induction, and peripheral blood from 20 patients with COPD were analyzed. DNA was extracted and analyzed for MSI using the following microsatellite markers: RH70958, D5S207, D6S344, D6S263, G29802, D13S71, D14S588, D14S292 and D17S250. Microsatellite analysis was also performed in 8 healthy nonsmokers. MSI was detected in the sputum samples of 7 patients with COPD (35\%). In contrast, no microsatellite DNA instability was noted in the nasal cytological samples of the same COPD patients. In addition, no genetic alteration was detected in the control group. These results suggest that MSI is a specific finding for the target organ of COPD, i.e. the lungs, despite the fact that inflammation coexists in the nasal mucosa of COPD patients. Our study supports the hypothesis that MSI could be an index of the somaticacquired genetic alterations in the lungs of COPD patients.
\end{abstract}

\section{Introduction}

Chronic obstructive pulmonary disease (COPD) constitutes a leading cause of morbidity and mortality among the adult population. It is a preventable and treatable disease state characterized by progressive airflow limitation that is not

Correspondence to: Dr A.D. Karatzanis, Department of Otorhinolaryngology, Head and Neck Surgery, University Hospital, Medical School, University of Crete, Heraklion 71110, Crete, Greece E-mail: akaratzanis@yahoo.com

Key words: microsatellite DNA, somatic mutation, cigarette smoking, sputum, nasal cytology, genetic susceptibility, chronic bronchitis, emphysema fully reversible. Cigarette smoking is undoubtedly the major risk factor of COPD. On the other hand, only a small fraction of smokers develop COPD, suggesting that, in addition to environmental factors, genetic susceptibility also plays an important role in the pathogenesis of the disease (1-3).

Deoxyribonucleic acid (DNA) microsatellites (MS) are highly polymorphic markers used for genome mapping in many organisms, including humans (4). Microsatellite DNA instability (MSI) has been initially reported in a number of human malignancies (5-7). During recent years such phenomena have also been detected in sputum cells of COPD patients, as well as in various other benign diseases (8-12). In addition, the detection of MSI in sputum cells of patients with COPD has been suggested to be disease specific in certain microsatellite markers, and could represent a useful marker of genetic susceptibility indicating destabilization of the genome at various loci (11).

The upper and lower respiratory airways form a continuous tract and share many anatomical and histological properties (13). Previous studies have shown that COPD is characterized by nasal inflammation with many similar features compared to the established bronchial inflammation $(14,15)$. The aim of this study was to assess the presence of MSI in nasal cytological samples of patients with COPD.

\section{Patients and methods}

A total of 20 patients with COPD were studied. The inclusion criteria for COPD and assessment of severity were in accordance with the recent ATS/ERS consensus statement (1). In addition to a history of smoking, all patients had a clinical history of cough and sputum, breathlessness on exertion, non-reversible obstruction on spirometry after $\beta_{2^{-}}$ agonist administration, and no history of atopy and asthma. Patients with any upper respiratory tract infection within the last 6 weeks before the study, as well as those with a history of lung (or other) cancer were excluded from this study. In addition, a control group was studied, consisting of 8 nonsmoking individuals with negative history and clinical examination for COPD and atopy.

Sputum samples, nasal cytological specimens, and peripheral blood samples were obtained from all patients. A standard brush method was used for all nasal cytological specimens and was performed by the same doctor $(12,16,17)$. 
Table I. The microsatellite DNA markers with corresponding chromosomal regions used in this study.

\begin{tabular}{|c|c|c|c|}
\hline $\mathrm{a} / \mathrm{a}$ & Microsatellite marker & Chromosomal location & Candidate gene \\
\hline 1 & RH70958 & $2 \mathrm{p} 12$ & CD8 antigen, $\beta$ polypeptide $1 \& 2$ \\
\hline 2 & D5S207 & $5 q 31.3-q 33.3$ & $\begin{array}{l}\text { Interleukin } 4 \text { (IL-4) } \\
\text { b2-adrenergic receptor }\end{array}$ \\
\hline 3 & D6S344 & $6 \mathrm{p} 25$ & $\begin{array}{l}\text { PI6, } \\
\text { PI9 }\end{array}$ \\
\hline 4 & D6S263 & $6 \mathrm{p} 23-\mathrm{p} 24.2$ & Endothelin-1 \\
\hline 5 & G29802 & $10 \mathrm{q} 22$ & PRF1 \\
\hline 6 & D13S71 & $13 q 32$ & Tumor necrosis factor ligand superfamily, member 13B \\
\hline 7 & D14S588 & $14 q 23-14 q 24$ & PTGDR [prostaglandin D2 receptor (DP)] \\
\hline 8 & D14S292 & $14 q 32.1-32.3$ & $\begin{array}{l}\alpha \text {-1-antitrypsin } \\
\alpha \text {-1-antichymotrypsin }\end{array}$ \\
\hline 9 & $\mathrm{D} 17 \mathrm{~S} 250$ & $17 q 11.2-q 12$ & $\begin{array}{l}\text { Apoptosis-antagonizing transcription factor } \\
\text { Serotonin transporter } \\
\text { Signal transducer and activator of transcription 5B (STAT5B) }\end{array}$ \\
\hline
\end{tabular}

Table II. Anthropometrical, clinical and laboratory characteristics of patients with COPD and healthy control subjects. ${ }^{a}$

\begin{tabular}{lcc}
\hline Patient data & COPD & Control \\
\hline Number of patients & 20 & 8 \\
Male/female & $16 / 4$ & $5 / 3$ \\
Age, year & $65 \pm 7$ & $55 \pm 18$ \\
Smoking, pack-year & $48 \pm 7$ & Non-smokers \\
FEV $_{1}(\%$ pred) & $54 \pm 23$ & $92 \pm 4^{\mathrm{b}}$ \\
FVC $\left(\%\right.$ pred) $_{\text {FEV }} /$ FVC (\% pred) & $74 \pm 21$ & $88 \pm 4^{\mathrm{b}}$ \\
\hline
\end{tabular}

${ }^{\mathrm{a}} \mathrm{Age}$ and spirometric values are expressed as mean $\pm \mathrm{SD} ;{ }^{\mathrm{b}} \mathrm{p}<0.05$.

Sputum was induced via inhalation of a hypertonic saline aerosol, generated by an ultrasonic nebulizer (Ultraneb 2000; DeVilbiss, Somerset, PA, USA) according to standard methods (18). All samples were stored at $-70^{\circ} \mathrm{C}$ for DNA extraction. DNA was extracted with the QIAamp (Qiagen extraction kits, QIAmp DNA blood maxi and mini kits, Qiagen Inc.) tissue and blood kits, following the manufacturer's instructions. DNA samples were stored at $4^{\circ} \mathrm{C}$.

Nine polymorphic microsatellite markers were used to assess MSI (RH70958, D5S207, D6S344, D6S263, G29802, D13S71, D14S588, D14S292 and D17S250), and are described in detail in Table I. All markers have been shown to be located closely to candidate genes involved in COPD pathogenesis $(4,10,19,20)$. The sequences of the microsatellite markers used were provided through the NCBI database (www.ncbi.nlm.nih.gov).
The polymerase chain reaction (PCR) technique was used to amplify DNA sequences. PCRs were performed in $50 \mu 1$ final volume reaction mixtures in a PTC-100 thermal cycler (M.J. Research Inc., Watertown, MA, USA), using the Qiagen Taq PCR core kit (Qiagen Inc.). Forward primers were labeled with the Licor IR800 fluorochrome. Reactions were denatured for $5 \mathrm{~min}$ at $95^{\circ} \mathrm{C}$ and the DNA was subsequently amplified for 30 cycles at $95^{\circ} \mathrm{C}, 55^{\circ} \mathrm{C}$ and $72^{\circ} \mathrm{C}$ during each step. The PCR products were analyzed and visualized by electrophoresis in $8 \%$ Long Ranger polyacrylamide (BMA, Rockland, ME, USA)/7 M urea sequencing gels in a Licor 4200 DNA sequencer (Lincoln, NE, USA). Alleles were sized with GeneProfiler v3.54 software (Scanalytics, USA). MSI was identified by comparing electrophoretic patterns of the microsatellite markers of DNA of nasal and sputum specimens versus peripheral blood demonstrating a shift of one or both of the alleles, thus, generating novel alleles as indicated by an addition or deletion of one or more repeat units. Two scientists who were not aware of the clinical characteristics of the subjects performed independent readings.

\section{Results}

The demographic parameters, smoking history, and mean spirometric values of both groups are shown on Table II. DNA was successfully extracted in satisfactory quantities from all cytological samples. Seven COPD patients (35\%) exhibited MSI in their sputum samples. The results of MSI in COPD patients are summarized on Table III. None of the control subjects exhibited MSI in their sputum samples. Furthermore, no genetic microsatellite alterations were noted in the nasal samples of either group. Fig. 1 shows representative electrophoretic patterns of microsatellite stability (MSS) in nasal 
Table III. MSI positive cases in sputum and nasal cytological samples, according to microsatellite marker, chromosomal region and subject group.

\begin{tabular}{|c|c|c|c|c|c|}
\hline \multirow[b]{3}{*}{ Microsatellite marker } & \multirow[b]{3}{*}{ Chromosome } & \multicolumn{4}{|c|}{ Microsatellite instability } \\
\hline & & \multicolumn{2}{|c|}{ COPD patients } & \multicolumn{2}{|c|}{ Normal subjects } \\
\hline & & Sputum $(n=20)$ & Nasal (n=20) & Sputum $(n=8)$ & Nasal $(n=8)$ \\
\hline RH70958 & $2 \mathrm{p} 12$ & 0 & 0 & 0 & 0 \\
\hline D5S207 & $5 q 31.3-5 q 33.3$ & 0 & 0 & 0 & 0 \\
\hline D6S344 & $6 \mathrm{p} 25$ & $1(5 \%)$ & 0 & 0 & 0 \\
\hline D6S263 & $6 \mathrm{p} 23-\mathrm{p} 24.2$ & $2(10 \%)$ & 0 & 0 & 0 \\
\hline G29802 & 10q22 & $1(5 \%)$ & 0 & 0 & 0 \\
\hline D13S71 & $13 q 32$ & 0 & 0 & 0 & 0 \\
\hline D14S588 & $14 q 22.1$ & $1(5 \%)$ & 0 & 0 & 0 \\
\hline D14S292 & $14 q 32.1-32.3$ & $2(10 \%)$ & 0 & 0 & 0 \\
\hline $\mathrm{D} 17 \mathrm{~S} 250$ & 17q11.2-q12 & 0 & 0 & 0 & 0 \\
\hline Total & & 7 & 0 & 0 & 0 \\
\hline
\end{tabular}
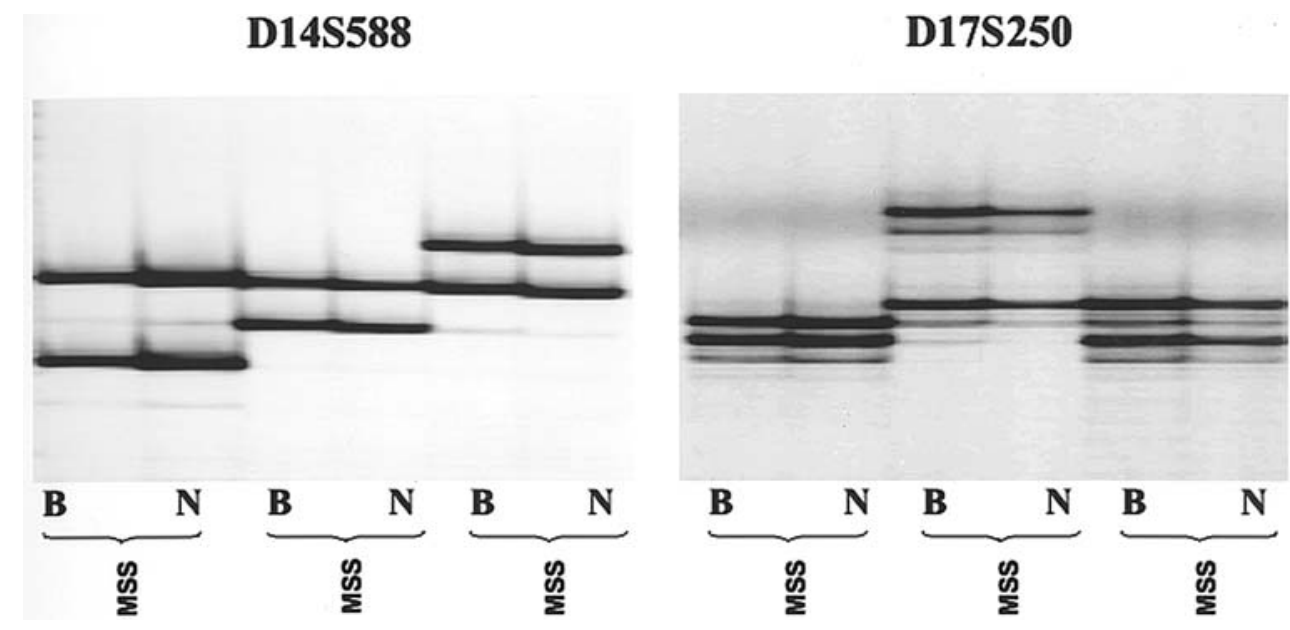

Figure 1. Representative electrophoretic patterns of microsatellite stability in two of the markers (D14S588, D17S250) tested. B, blood-extracted DNA; N, nasal-extracted DNA; MSS, microsatellite stability.

samples of COPD patients, while Fig. 2 represents an example of microsatellite instability (MSI) in sputum samples of the same COPD patients.

\section{Discussion}

Chronic obstructive pulmonary disease (COPD) is a preventable and treatable disease state characterised by airflow limitation that is not fully reversible. Although COPD affects the lungs, it also produces significant systemic consequences (1).

Despite the significant association of smoking and COPD, few smokers develop clinically relevant COPD, suggesting a genetically predetermined susceptibility. Linkage and candidate gene studies in COPD suggested a number of candidate genes to be involved in COPD pathogenesis $(10,11,21)$.

Genomic MS are repetitions of simple 1-6 bp nucleotide sequences that have been detected in both prokaryotic and eukaryotic cells (22-24). The genomic MS are associated with high mutation rates. With the use of polymerase chain reaction (PCR) technology, microsatellite DNA has been converted into a highly versatile genetic marker with a wide range of applications (4).

Recent studies from our laboratory have shown that somatic genetic alterations such as MSI are detectable phenomena in sputum cells of COPD patients. Furthermore, it has been suggested that MSI could be considered as a useful marker of genetic susceptibility for COPD indicating destabilization of the genome at various loci $(3,4,10,11)$. This destabilization has been hypothesized to be the result of oxidative stress in COPD which not only creates DNA adducts that are potentially mutagenic, but also 'relaxes' the mechanisms that limit the DNA damage by suppressing key genes of the DNA mismatch repair (MMR) system. Thus, varying efficiency of DNA repair could be viewed as a potential determinant of disease susceptibility (11). This hypothesis is supported by 


\section{D14S292}

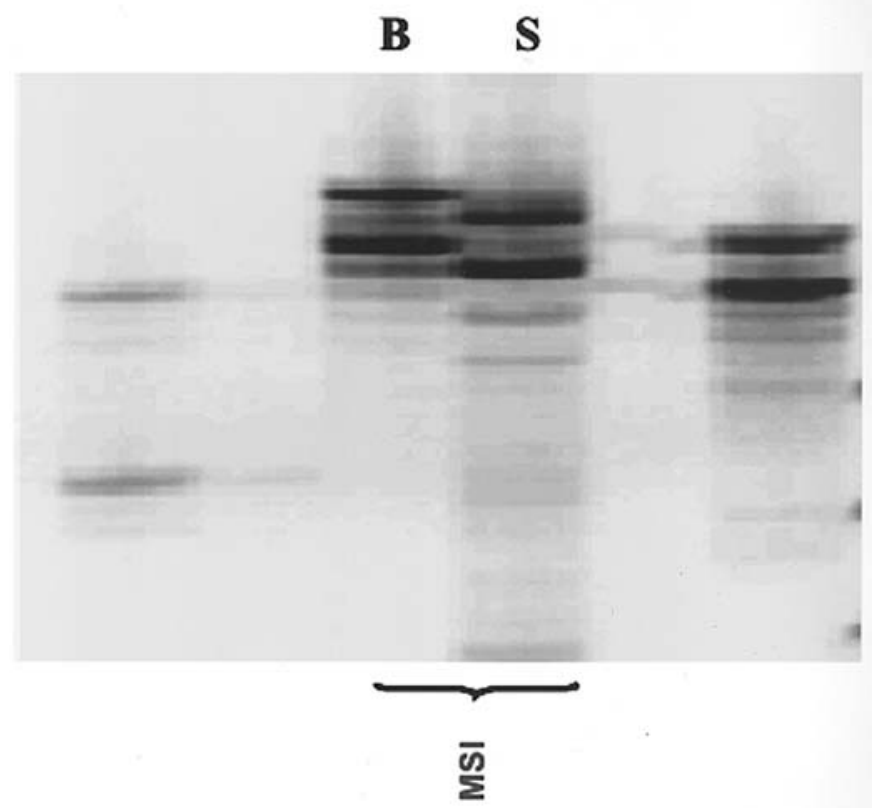

Figure 2. An example of microsatellite instability in one of the markers (D14S292) tested. B, blood-extracted DNA; S, sputum-extracted DNA; MSI, microsatellite instability.

findings regarding other diseases, such as rheumatoid arthritis and ulcerative colitis $(25,26)$.

The aim of the present study was to assess the presence of MSI in nasal cytological samples of patients with COPD. The upper and lower respiratory airways form a continuous tract and share many anatomical and histological properties (13). Previous studies have shown that COPD is characterized by nasal inflammation with many similar features compared to the established bronchial inflammation $(14,15)$.

Therefore, 9 microsatellite markers RH70958, D5S207, D6S344, D6S263, G29802, D13S71, D14S588, D14S292 and D17S250, located on chromosomal regions 2p12, 5q31.3-q33.3, 6p25, 6p23-p24.2, 10q22, 13q32, 14q23-q24, $14 q 32.1-q 32.3$ and 17q11.2-q12 were chosen. These locations are implicated according to recent literature, with candidate and/or susceptibility genes for COPD $(4,10,11,19-21,27,28)$. More specifically, chromosomal region 2 p12 has been related with the CD8 antigen. The G29802 marker is located at the chromosomal position 10q22 encoding the perforin protein. Perforin is considered the main mediator of the membranolytic action of cytotoxic $\mathrm{CD}^{+}$lymphocytes and it is implicated in the apoptotic and destructive process leading to the development of COPD (27). Marker D6S344 is located at chromosomal region $6 \mathrm{p} 25$ where proteinase inhibitors 6 and 9 (PI-6 and PI-9) are also located. These members of the serpin superfamily have been shown to prevent cellular damage by scavenging leaking lysosomal proteases (28). Furthermore, the chromosomal region $14 q 32.1-32.3$ has been suggested to harbor $\alpha-1$-antitrypsin and $\alpha$-1-antichymotrypsin genes (21). Moreover, recent studies have suggested susceptibility genes for COPD, on chromosomes 5q31.3, $6 \mathrm{p} 23,13 \mathrm{q} 32$, and $14 \mathrm{q} 23$, i.e. the interleukin 4 , the b2 adrenergic receptor, the tumor necrosis factor superfamily, and the apoptosis antagonizing factor $(11,21)$ (Table I). All microsatellite markers used in the present study are located in the prementioned chromosomal regions.

It has been reported that patients with COPD present with inflammation of the nasal mucosa which is characterised by an increased number of CD8 T lymphocytes, neutrophils and macrophages. In addition, squamous cell metaplasia is the major structural change associated with nasal inflammation in patients with COPD. Overall, many similarities have been noted both in the inflammatory pattern and in structural changes including squamous cell metaplasia between the nose and bronchi of COPD patients (14). Given these similarities, we conducted a study comparing nasal and bronchial alterations of COPD patients at the microsatellite level. Although MSI was detected in sputum samples of the COPD group as expected, no microsatellite genetic alterations were detected in the nasal cytological samples of COPD patients.

Recently, we attempted to detect MSI in nasal cytological specimens of patients with allergic rhinitis (12). This attempt was based on pre-existing knowledge of the presence of such genetic alterations in sputum samples of patients with bronchial asthma in addition to the well established relationship between allergic rhinitis and asthma $(4,8,11,12)$. Nevertheless, results in nasal cytology of patients with allergic rhinitis were negative for MSI. We had attributed the failure to detect MSI mainly to differences in the remodeling patterns between the upper and lower airways in allergic rhinitis and asthma, respectively (12).

A possible limitation of the present study could be the small total number of samples. However, this was a pilot study assessing microsatellite instability in upper and lower airways of COPD patients. Moreover, 9 different microsatellite markers located in several chromosomal regions implicated with COPD pathogenesis were studied.

In conclusion, our results could suggest that MSI in certain chromosomal loci is not only disease specific as has been previously reported, but is also specific for the target organ of COPD, i.e. the lung. Therefore, if microsatellite DNA has a functional protective role thus 'shielding' DNA from environmental hazards, as previously hypothesized $(14,29)$, this role is lost through genetic alterations that take place specifically in the lower airways. Our results further strengthen the hypothesis that MSI could be a useful genetic screening tool in molecular epidemiology identifying smokers susceptible to $\mathrm{COPD}$.

\section{Acknowledgements}

This work was financially supported by an unrestricted grant from GSK.

\section{References}

1. Celli BR and MacNee W: Standards for the diagnosis and treatment of patients with COPD: a summary of the ATS/ERS paper. Eur Respir J 23: 932-946, 2004.

2. Siafakas NM, Vermeire P, Pride NB, et al: Optimal assessment and management of chronic obstructive pulmonary disease (COPD). Eur Respir J 8: 1398-1420, 1995.

3. Siafakas NM and Tzortzaki EG: Few smokers develop COPD. Why? Respir Med 96: 615-624, 2002. 
4. Samara K, Zervou M, Siafakas NM and Tzortzaki EG: Microsatellite DNA instability in benign lung diseases. Respir Med 100: 202-211, 2006.

5. Loeb LA: Microsatellite instability marker of a mutator phenotype in cancer. Cancer Res 54: 5059-5063, 1994.

6. Field JK, Kriaris H, Howard P, et al: Microsatellite instability in squamous cell carcinoma of the head and neck. Br J Cancer 75: 1065-1069, 1995 .

7. Loeb LA and Christian FC: Multiple mutation in human cancer. Mutation Res 350: 279-286, 1996.

8. Paraskakis E, Sourvinos G, Passam F, et al: Microsatellite DNA instability and loss of heterozygosity in bronchial asthma. Eur Respir J 22: 951-955, 2003.

9. Spandidos DA, Ergazaki M, Hatzistamou J, et al: Microsatellite instability in patients with chronic obstructive pulmonary disease. Oncol Rep 3: 489-491, 1996.

10. Siafakas NM, Tzortzaki EG, Sourvinos G, et al: Microsatellite DNA instability in COPD. Chest 116: 47-51, 1999.

11. Zervou M, Tzortzaki EG, Makris D, et al: Differences in Microsatellite DNA level between asthma and COPD. Eur Respir J 28: 472-478, 2006.

12. Karatzanis AD, Samara KD, Zervou M, Tzotrtzaki E, Helidonis ES, Siafakas N and Velegrakis GA: Assessment for microsatellite DNA instability in nasal cytology samples of patients with allergic rhinitis. Am J Rhinol (In press).

13. Gaga M, Vignola AM and Chanez P: Upper and lower airways: similarities and differences. Eur Respir Mon 18: 1-15, 2001.

14. Vachier I, Vignola AM, Chiappara G, et al: Inflammatory features of nasal mucosa in smokers with and without COPD. Thorax 59: 303-307, 2004.

15. Maestrelli P, Saetta M, Mapp C and Fabbri L: Remodeling in response to infection and injury. Airway inflammation and hypersecretion of mucus in smoking subjects with chronic obstructive pulmonary disease. Am J Respir Crit Care Med 164: S76-S80, 2001.

16. Pipkorn U, Karlsson G and Enerback L: A brush method to harvest cells from the nasal mucosa for microscopic and biochemical analysis. J Immunol Methods 112: 37-42, 1988.

17. Howarth PH, Persson CGA, Meltzer EO, et al: Objective monitoring of nasal airway inflammation in rhinitis. J Allergy Clin Immunol 115: S414-S441, 2005
18. Tsoumakidou M, Tzanakis $\mathrm{N}$ and Siafakas NM: Induced sputum in the investigation of airway inflammation of COPD. Respir Med 97: 863-871, 2003.

19. Anderson GP and Bozinovski S: Acquired somatic mutations in the molecular pathogenesis of COPD. Trends Pharmacol Sci 24: 71-76, 2003

20. Chizhikov VV, Chikina SIu, Tatosian AG, Chuchalin AG and Zborovskaia IB: Development of chronic obstructive pulmonary disease correlates with mini- and microsatellite locus instability. Genetika May 39: 694-701, 2003.

21. Molfino AN: Genetics of COPD. Chest 125: 1929-1940, 2004.

22. Jaworski A, Rosche WA, Gellibolian R, et al: Mismatch repair in Escherichia coli enhances instability of (CTG)n triplet repeats from human hereditary diseases. Proc Natl Acad Sci USA 92: 11019-11023, 1995

23. Epplen C, Meimer G, Siedlaczck I, et al: On the essence of 'meaningless' simple repetetive DNA in eukaryote genomes. In: DNA fingerprinting: state of the science. EXS 67: 29-45, 1993.

24. Metzgar D, Bytof J and Wills C: Selection against frame shift mutations limits microsatellite expansion in coding DNA. Genome Res 10: 72-80, 2000.

25. Hofseth LJ, Khan MA, Ambrose M, et al: The adaptive imbalance in base excision-repair enzymes generates microsatellite instability in chronic inflammation. J Clin Invest 112: 1887-1894, 2003.

26. Lee SH, Chang DK, Goel A, Boland CR, Bugbee W, Boyle DL and Firestein GS: Microsatellite instability and suppressed DNA repair enzyme expression in rheumatoid arthritis. J Immunol 170: 2214-2220, 2003.

27. Trapani JA and Sutton VR: Granzyme B: pro-apoptotic, antiviral and antitumor functions. Curr Opin Immunol 15: 533-543, 2003.

28. Strik MC, Wolbink A, Wouters D, Bladergroen BA, Verlaan AR, van Houdt IS, Hijlkema S, Hack CE and Kummer JA: Intracellular serpin SERPINB6 (PI6) is abundantly expressed by human mast cells and forms complexes with beta-tryptase monomers. Blood 103: 2710-2717, 2004.

29. Martin P, Makepeace K, Hill SA, Hood DW and Moxon ER: Microsatellite instability regulates transcription factor binding and gene expression. Proc Natl Acad Sci USA 102: 3800-3804, 2005 . 